\title{
The global analysis of a structure on the basis of precast building
}

\author{
Teresa Grabiec-Mizera ${ }^{1}$, Michał Kaczmarczyk ${ }^{2}$, Mieczysław Kuczma ${ }^{3}$ \\ ${ }^{1,3}$ Institute of Structural Engineering, Faculty of Civil and Environmental Engineering, \\ Poznan University of Technology, Poznan, Poland \\ ${ }^{2}$ Constravia Sp. z o.o. (Private Limited Company), Poznan, Poland \\ E-mail: 'leresa.grabiec-mizera@put.poznan.pl (corresponding author)
}

\begin{abstract}
The aim of the paper is to present a global analysis of a precast, reinforced building structure. At the design stage, information about structural behaviour of particular elements and the whole structure as well as its response to applied loads are obtained. While solving the problem, the load-bearing elements and the type and deformability of connections have to be defined. The latter is especially significant in the case of precast structure models. Calculations according to the analytical method are going to be verified by the finite element method.
\end{abstract}

Keywords: global analysis, precast technology, stiffness.

\section{Introduction}

Structural analysis involves principles to determine appropriate models describing the shape and static scheme of a structure as well as the static calculations. The second order effects as a result of influence of geometrical non-linearity can be taken into account in the global analysis or in the calculations of separated elements. It is important to include the second order effects in the cases of elements subjected to compression.

The structure is analysed globally according to the first order theory. An increase of bending moments due to the second order effects is included in the analysis of separated elements. Such an approach is conforming with the EC2 standard when the conditions allowing to neglect the global second order effects are met. They can be neglected when their contribution is lower than $10 \%$ of the corresponding first order results. EC2 proposes this simplifying condition based on the $10 \%$ contribution rule. If it is not met, than the global second order analysis is necessary (European Committee for Standardization [CEN], 2008).

The paper presents the problem of a global analysis of a structure made of precast reinforced concrete. The analysis of such a structure yields its response to the applied predefined combinations of loading. Information related to particular structural elements and to the entire structure is obtained. The designer is informed about the type of structural response, ways of load transmission and deformations. To this end the load bearing structural elements as well as the type and flexibility of connections must be defined. In the case of precast structures this information is obtained in an iterative way.

The majority of connections between precast elements feature some flexibility and they cannot be treated as rigid ones. It is necessary to take this fact into account in the global analysis to get a correct distribution of internal forces in the elements. Filling of the connections which are not designed (reinforced) to carry any loads will lead to occurrence of forced cracking therein. This in turn leads to the forces redistribution.

\section{Analysis of cracks influence on stiffness and deflection of precast reinforced concrete structure}

Structures are subjected to various types of loading. They can be vertical, horizontal or combined. Horizontal forces can result from wind action, soil pressure, special loads and imperfections. In the structural analysis one has to take into account the way in which a particular load is transmitted from the point of its application to the foundation. A correct design of a structure requires a definition of elements dimensions as well as the connections between them (Vinje, 2016). This problem is especially important in the case of precast structures (Figure 1). It is assumed that the element connections are cracked and concrete as the filling material does not carry any tensile stress. However, during the service of such an element subjected to bending, some tensile stress results. When the concrete tensile strength is exceeded then cracking occurs. The crack location is determined by the location of a horizontal joint. The subsequent increase of the bending moment leads to cracking of the element itself. 


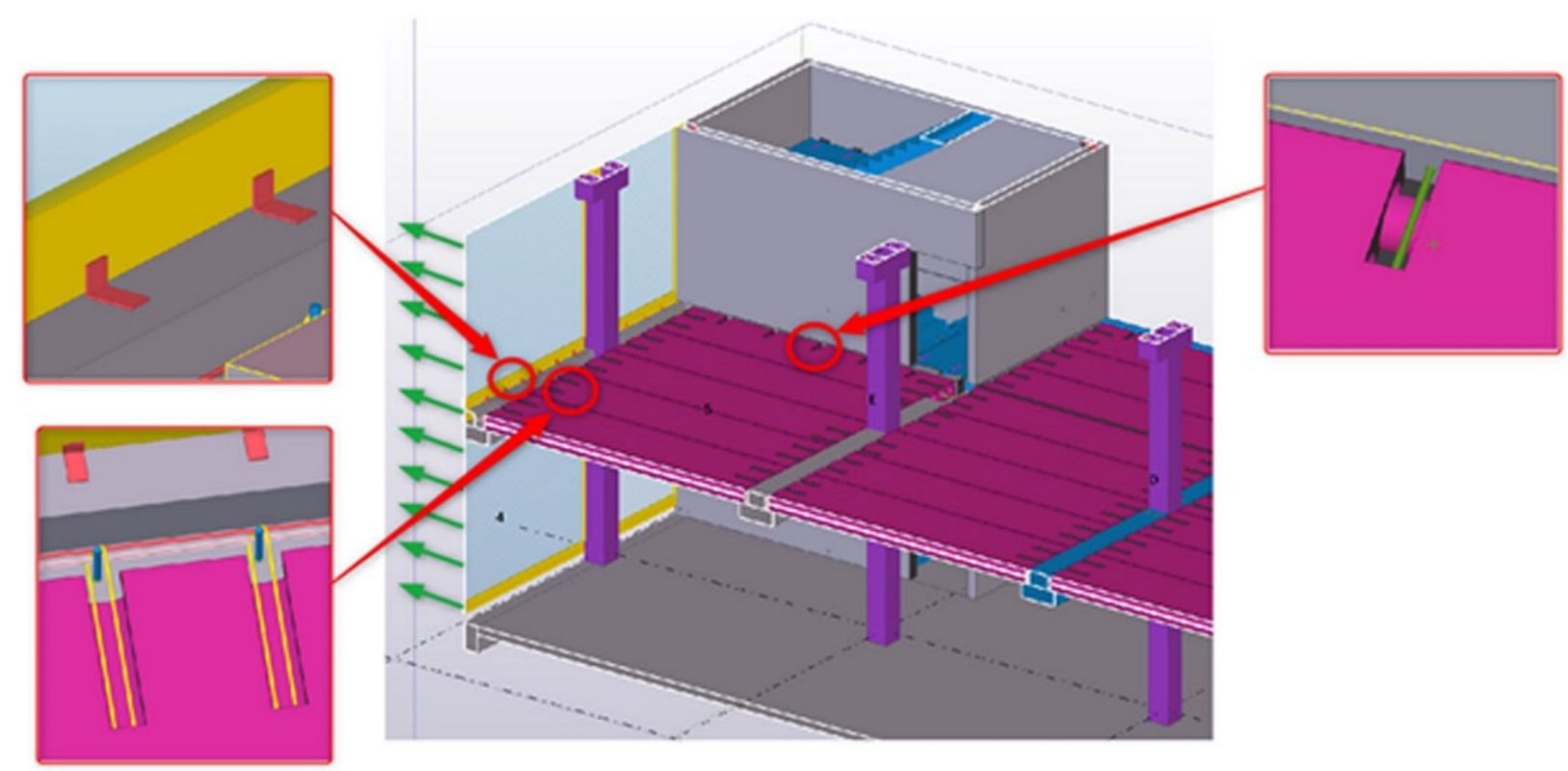

Figure 1. Elements connections during forces transfer

A properly designed plane stress element must ensure the structural safety both in the ultimate limit state and in the serviceability limit state with the second order effects taken into account. In the calculation and checking of the deflection of such an element the internal forces distribution in all the stiffening elements must be determined with their stiffness taken into account.

The element deflection is influenced by its flexural and shear stiffness. With the increasing slenderness the contribution of the shear effects decrease. The flexural stiffness depends on the cracking state of the element. Increase of the bending stiffness is possible by increasing of the cross-section dimensions, concrete class, amount of reinforcement and compressive stress in the cross-section. The calculations are based on the determination if the element remains in the uncracked state (phase I) or in the cracked state (phase II) when subjected to the given load (Lapko \& Jensen, 2009; International Federation for Structural Concrete (fib), 2013).

In the paper the analysis of a plane-stress element - the wall subjected to a horizontal in its plane force, was carried out (Kaczmarczyk, 2018). In this case the forces from floors and lining are transmitted to the foundations. In the determination of cross-sections characteristics the influence of adjacent walls or corners was neglected. However, in all the cases, one has to analyse if the interaction with the surrounding elements of the structure is required. The following formulae were used in the general calculations of deflections:

1. - general curvature

$$
\frac{1}{R}=\frac{M}{E c \cdot I}
$$

2. - slope

$$
\phi=\int_{0}^{L} \frac{1}{R} d z
$$

3. - deflection

$$
f=\int_{0}^{L} \phi d z
$$

For the integration purposes the element was subdivided into fragments with height equal to the storey height. When using the computer programs in the static analysis, the stiffness changes due to cracking can be taken into account by varying parameters for the elements, i.e. by a modification of geometry or material properties.

In the performed analyses linear and non-linear models were applied (Figure 2, Figure 3).

1. Linear uncracked model.

2. Linear model with cracking over the entire cross-section depth. The element stiffness was equal to the stiffness of the most cracked cross-section. Interaction between cracks was neglected.

3. Linear model with cracking over the entire cross-section depth. The element stiffness was averaged (for phases I and II). Interaction between cracks included. 
4. Linear model with cracking over the entire cross-section depth, where the bending moment exceeds the value of the cracking moment. Two values of stiffness used - that for the uncracked cross-section and the averaged one for the cracked cross-section. Interaction between cracks included.

5. Linear model with cracking. Stiffness reduction included at the zones where the bending moment exceeded the value of the cracking moment. Stiffness determined separately for each story where cracking occurred.
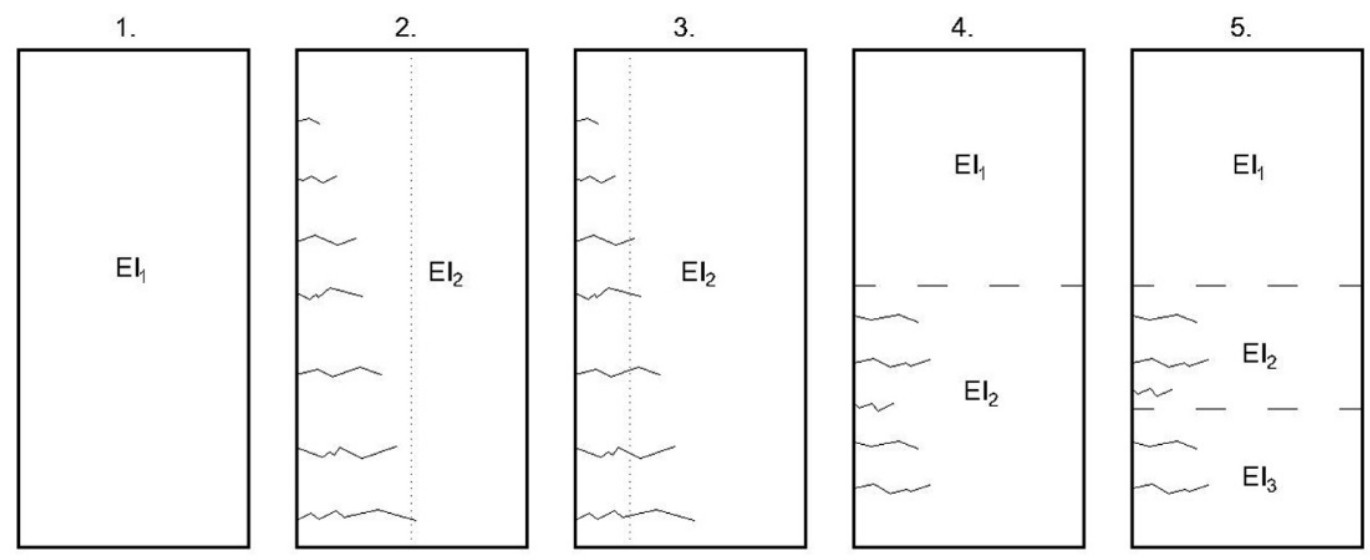

Figure 2. Linear models schemes

6. Non-linear uncracked model. It was assumed that horizontal joints do not carry tensile stress.

7. Non-linear model with cracking and with varying stiffness at the cracked floors. Cross-section stiffness taken from the moments obtained by the linear analysis.

8. Non-linear model with cracking and with varying stiffness at the cracked floors. Cross-section stiffness updated for moments obtained by the non-linear analysis.
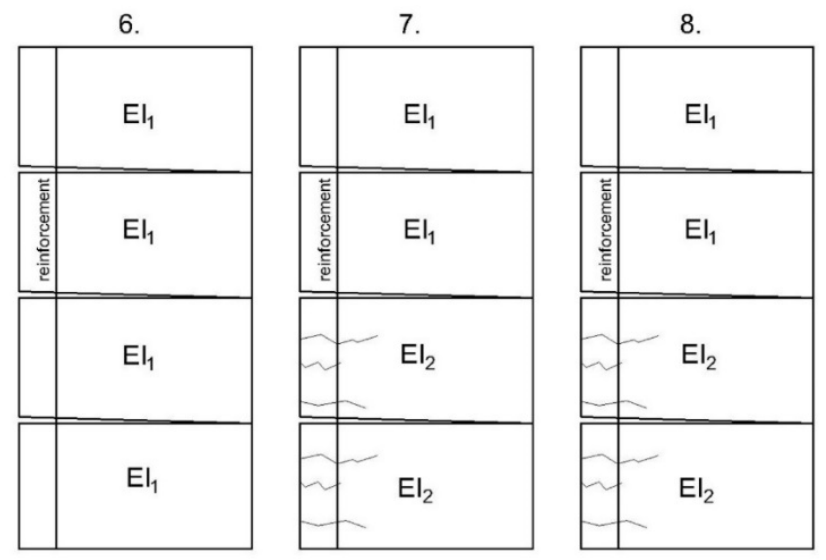

Figure 3. Non-linear models schemes

The cross check analysis by the FEM was carried out using the shell and beam models for the linear cases and the shell model only in the non-linear cases. The calculations were done using the program ROBOT. The shell with constant thickness of $200 \mathrm{~mm}$ was assumed and the edge loading of $10 \mathrm{kN} / \mathrm{m}$ was applied. The shell was discretized using the square finite elements with the dimension of $250 \mathrm{~mm}$. Stiffness changes were controlled by the matrix reduction. The bar model was assumed as the bar with the dimensions of $3000 \times 200 \mathrm{~mm}$, loaded in the same way as the shell. Stiffness changes were controlled by a modification of the cross-section depth. Table 1 presents the results of the maximal deflection obtained within the linear and non-linear analyses as well as the FEM verification.

The smallest deflection is obtained for the uncracked linear model, whereas the largest one - with the assumption that the cross-section parameters over the entire height of the element are reduced to the values corresponding to the cracked phase without interaction between the cracks. However, an intermediate model is correct for the real behaviour of structures. There are many factors, not always taken into account in the analyses, influencing the real deformation of structures. 
Table 1. Values of maximal deflection

\begin{tabular}{|c|c|c|}
\hline \multirow{2}{*}{ Model } & \multicolumn{2}{|c|}{ Deflection } \\
\cline { 2 - 3 } & Analytical method & FEM \\
\cline { 2 - 3 } & {$[\mathrm{m}]$} & {$[\mathrm{m}]$} \\
\hline 1 & $\mathbf{0 . 0 6 8 2}$ & $\mathbf{0 . 6 6 9}$ \\
\hline 2 & $\mathbf{0 . 9 4 8 8}$ & $\mathbf{0 . 9 5 8 5}$ \\
\hline 3 & 0.91424 & 0.9239 \\
\hline 4 & 0.8888 & 0.9 \\
\hline 5 & 0.8236 & 0.8393 \\
\hline 6 & - & 0.0974 \\
\hline 7 & - & 0.7842 \\
\hline 8 & - & 0.7536 \\
\hline
\end{tabular}

\section{Global analysis of a precast structure}

The considerations were carried out for a four-storey building, with a plate-column structure, designed as a precast one, with dimensions of $24.4 \times 24.4 \mathrm{~m}$ in the plan view (Figure 4) (Kaczmarczyk, 2018).
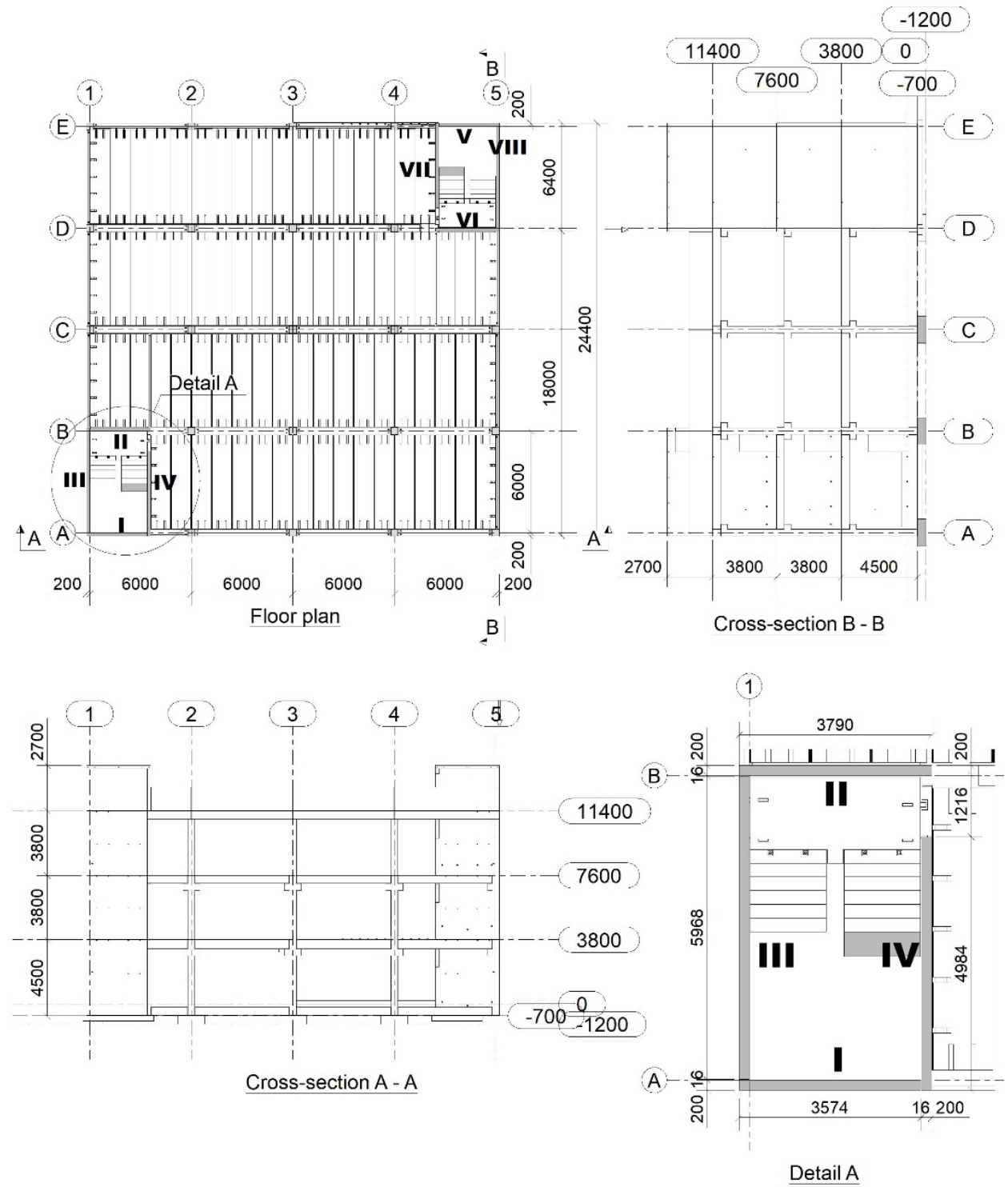

Figure 4. Structure scheme 
The horizontal plates were built from channel slabs supported at beams and consoles. The load bearing walls were $200 \mathrm{~mm}$ thick and the columns had the cross-section dimensions of $400 \times 400 \mathrm{~mm}$. Elevation lining is of the lightweight type suspended from the structure. There are two communication shafts, made as precast, which stiffen the structure. Horizontal wind load is carried from the elevation walls onto ceiling slabs and further to the shaft walls. Vertical loading comes from the dead weight, the weight of the other structural elements besides walls, imposed load and snow load. Horizontal load is due to wind. The loading schemes for walls were assumed as described above.

Standard formulae according to EC2 were used to take into account the influence of geometrical imperfections expressed in terms of transverse loading added to the other loading in the calculations (CEN, 2008).

The imperfections influence on the stiffening system was expressed as:

$$
H_{i}=\theta_{i}\left(N_{b}-N_{a}\right) \text {. }
$$

The influence of imperfections on the floor slab is given by:

$$
H_{i}=0,5 \theta_{i}\left(N_{b}+N_{a}\right)
$$

The influence of imperfections on the roof slab is given by:

$$
H_{i}=\theta_{i} N_{a},
$$

where: $N_{a}$ and $N_{b}$ are the longitudinal forces influencing $H_{i}$. The largest forces due to imperfections occur at the lowest storey. Their values were adopted for the higher storeys to simplify the computations.

The purpose of the global analysis was in determination of forces in the bracing elements, i.e. those which carry the horizontal forces as per assumptions. It was also assumed that all the horizontal forces are transmitted to two staircase shafts. The presence of columns was not taken into account in the transmission of horizontal forces. The analytical method allowed for determination of forces distribution in the shaft walls (Figure 5, Figure 6).

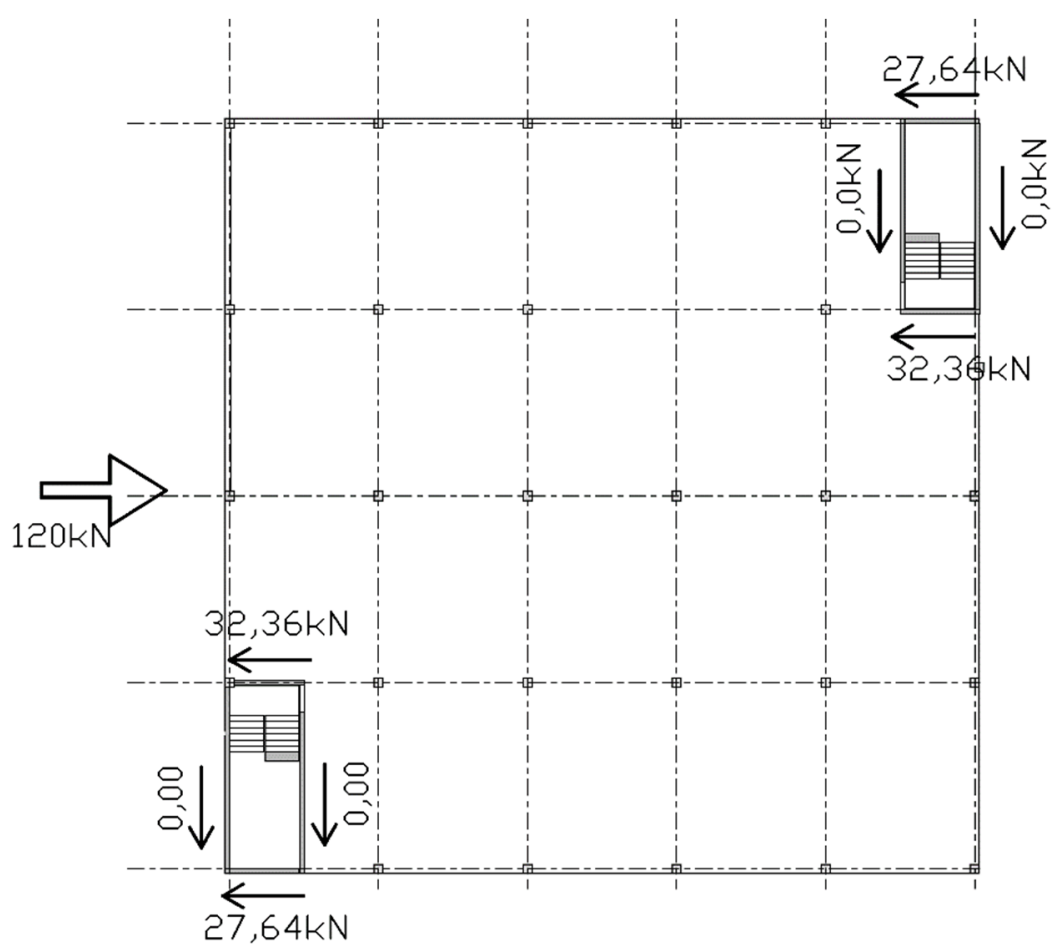

Figure 5. Forces distribution in braces $-\mathrm{Y}$ direction

Verification of analytical calculation was done using the FEM model formed with the same assumptions (Kaczmarczyk, 2018). The horizontal elements (floors) transmit the horizontal forces only to the vertical elements (walls). The walls stand under compression, and carry the bending moments and shear forces in their planes. The model was loaded by a horizontal force at the level of the highest storey. Within the adopted assumptions a coincidence of results from the analytical method and FEM was observed. It proves that one can assess the forces in braces using the linear-elastic model (Figure 7, Figure 8). 


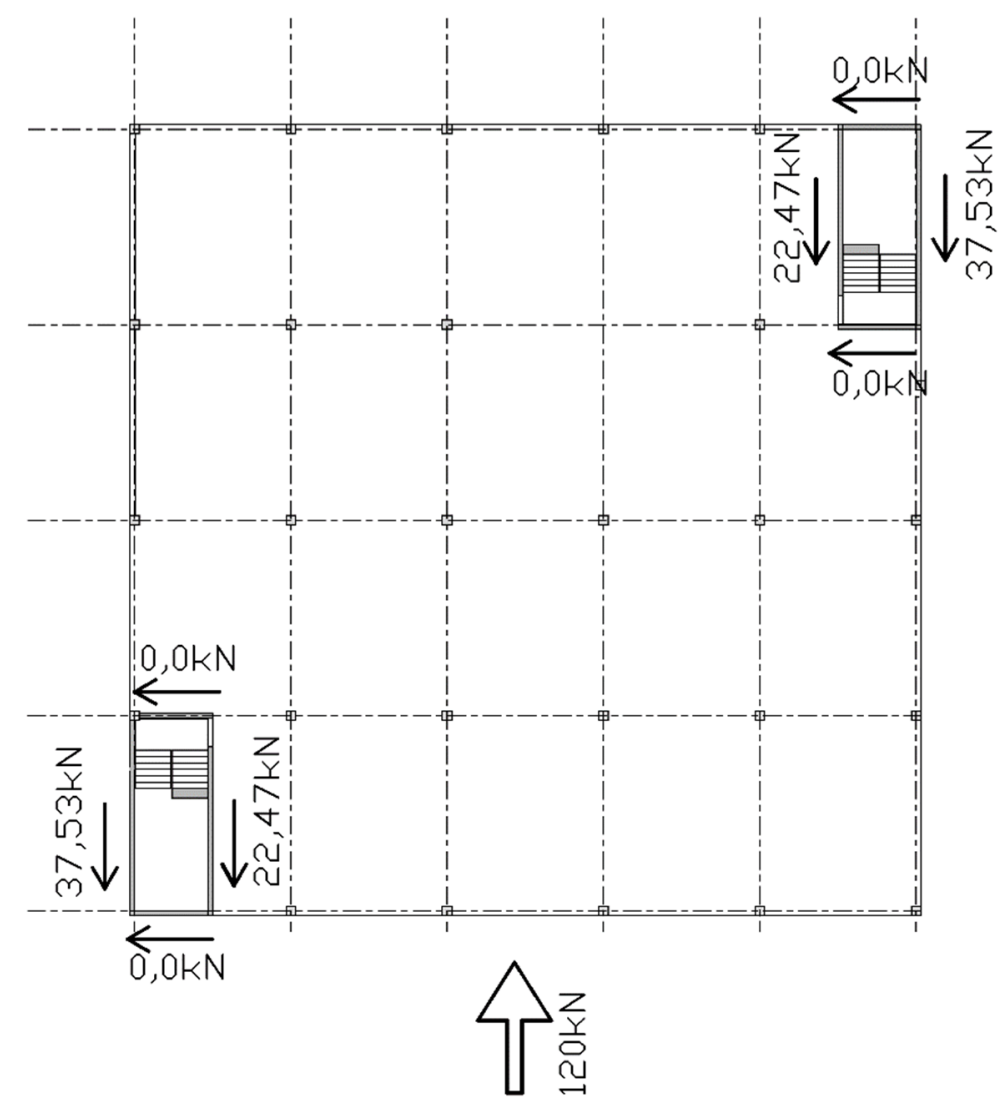

Figure 6. Forces distribution in braces $-\mathrm{X}$ direction

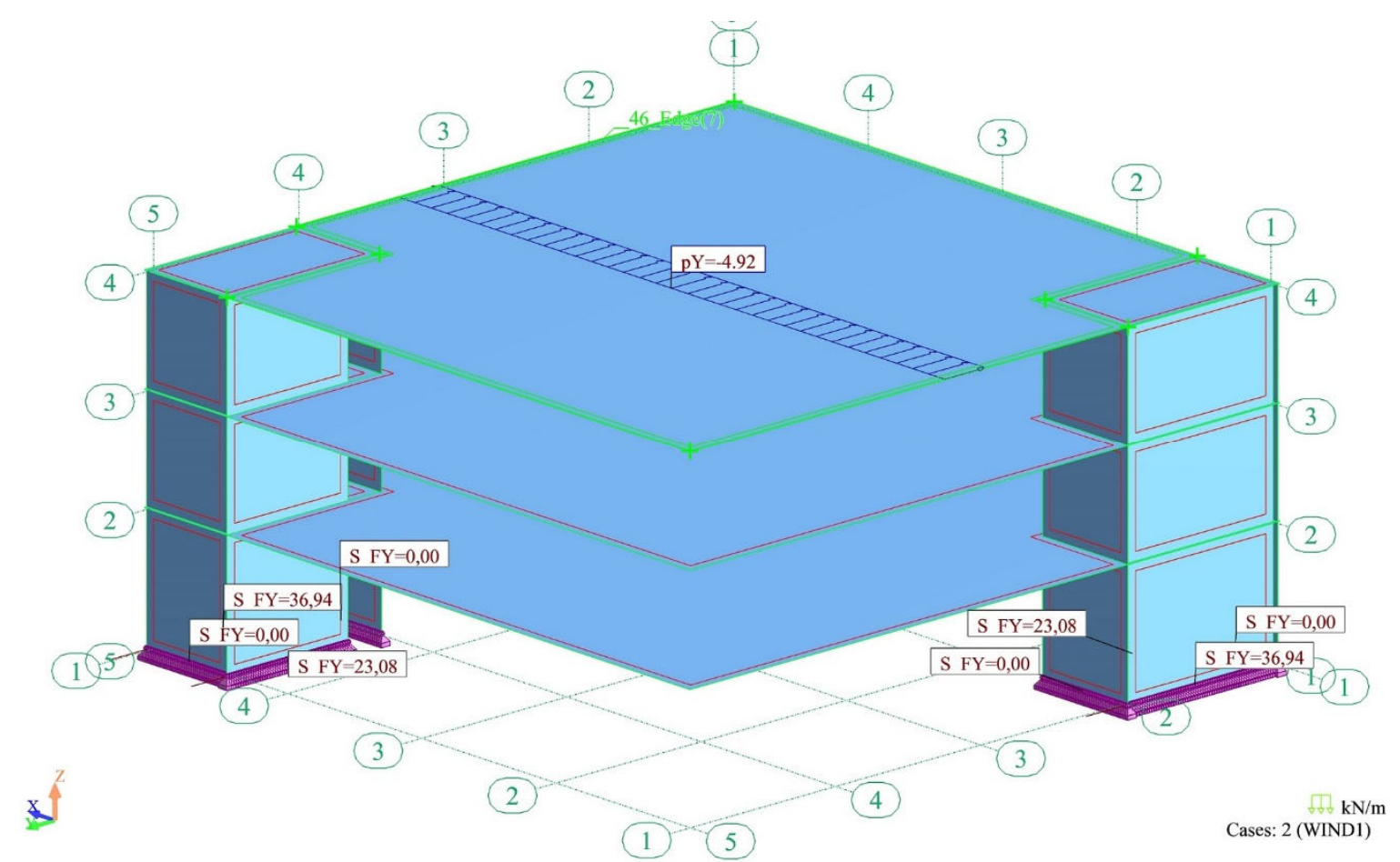

Figure 7. Forces distribution in braces $-\mathrm{Y}$ direction 


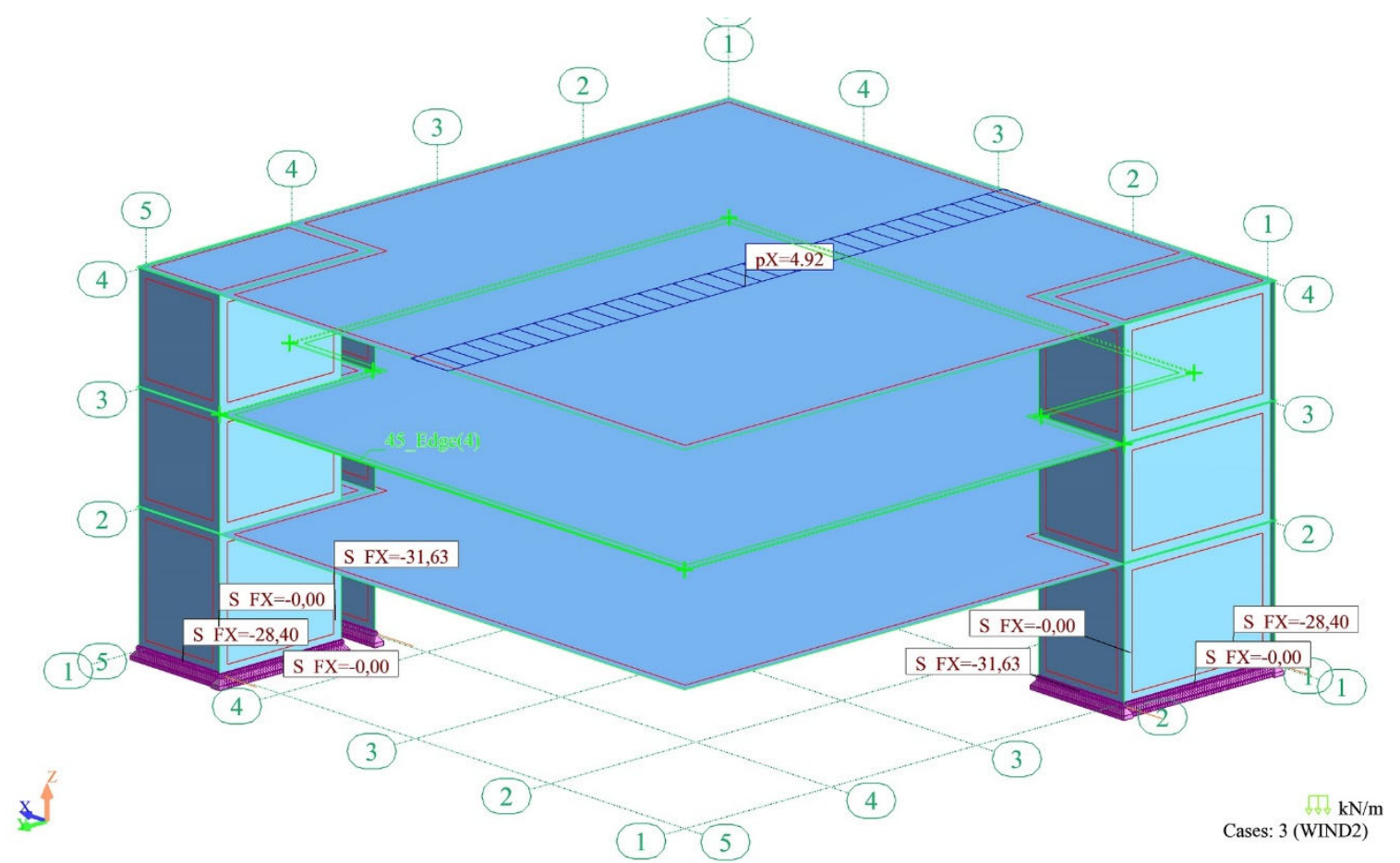

Figure 8 . Forces distribution in braces $-\mathrm{X}$ direction

\section{Conclusions}

Two calculation methods - analytical one and its verification based on FEM, were presented in the paper. The coincident values were received as a result of the analytical method and FEM calculations. The purpose was to emphasize the necessity to analyse the calculations obtained from computer programs. The program is intended to confirm or add details to the calculations by the analytical methods. The principles for elaboration of calculation models allowing to assess stiffness according to EC2 can be applied in the global analysis, too. Neglecting of cracks in reinforced concrete elements or in connections can lead to underestimation of deflections and sway. Also, neglecting of stiffness variation in particular elements due to applied loading, leads to erroneous evaluation of forces redistribution. This can result in exceeding of load bearing capacity of an element or the entire structure in service.

\section{Acknowledgements}

This work was supported by the project [01/11/SBAD/0027].

\section{References}

European Committee for Standardization. (2008). Eurocode2: Design of Concrete Structures - Part 1-1: General rules and rules for buildings (EN-1992-1-1). CEN, European Committee for Standardization, Brussels.

International Federation for Structural Concrete (fib). (2013). fib Model Code for Concrete Structures 2010: Final draft. International Federation for Structural Concrete (fib).

Łapko, A., \& Jensen, B. Ch. (2009). Podstawy projektowania i algorytmy obliczeń konstrukcji żelbetowych. Warszawa Arkady (in Polish).

Kaczmarczyk, M. (2018). Analiza globalna i wymiarowanie połaczeń w obiekcie o konstrukcji prefabrykowanej [Global analysis of precast structure and design of connections] (Master thesis). Poznan University of Technology (in Polish).

Vinje, L. (2016). Betongelementboken, Bind B - Avstivning og kraftoverføring. Betongelementforeningen. 